\title{
O paradigmático caso do processo às juntas militares argentinas*
}

\author{
The paradigmatic case of the legal proceeding against \\ Argentina's Military Junta
}

Jorge D. BARrientos-PARRA

Doutor em Direito pela Université Catholique de Louvain, Mestre pela Universidade de São Paulo. Professor do Programa de Mestrado em Direito da Faculdade de Ciências Humanas e Sociais da Unesp, Campus de Franca. Professor de Direito Constitucional e de Direito Administrativo do curso de Administração Pública da Unesp, Campus de Araraquara. Professor visitante da Université Montesquieu - Bordeaux IV. barrientos@fclar.unesp.br

Resumo Este artigo pretende analisar o caso do processo contra as juntas militares argentinas que levou ao cárcere os responsáveis por crimes hediondos praticados durante o período da ditadura militar. O referido processo tem um alto valor simbólico na luta pelo respeito aos direitos humanos na América Latina e ganha relevância e atualidade no Brasil quando se discute a questão do direito à verdade envolvendo o tema dos desaparecidos na época do regime militar e o debate sobre a invalidação da Lei de Anistia (Lei No 6.683, de 28 de agosto de 1979) no que tange aos crimes comuns de tortura, violação e/ou sequestro, entre outros. No caso argentino, o Tribunal, seguindo a doutrina de Roxin da autoria mediata, considerou que os crimes foram cometidos pelos militares mediante a utilização de um aparato organizado de poder e afastou, de maneira enfática, as alegações de que os delitos teriam justificação na denominada "guerra suja". Nesse sentido, este processo contra as juntas militares passou a ser um caso paradigmático, não somente na Argentina, em que muitos chefes militares tiveram que responder a ações criminais, mas para todos os países da região, que enfrentaram situações semelhantes em sua história recente.

Palavras-chave: DIREITOS hUMANOS; PROCESSO PENAL; ARGENTINA; JUNTAS MILITARES; JULGAMENTOS; AUTORIA MEDIATA.

\footnotetext{
* A sentença completa encontra-se disponível em: <http://www.derechos.org/nizkor/arg/causa13/>. Acesso em: 13 abr. 2012.
} 
Abstract This article analyzes the case of the proceedings against Argentina's Military Juntas that led to jail those responsible for heinous crimes committed during the military dictatorship. The said proceeding has a high symbolic value in the struggle for human rights in Latin America and is relevant and timely in Brazil where the right to the truth regarding the missing people during the military dictatorship is in debate, as well as the invalidation of the Amnesty Act regarding the common crimes of torture, rape and / or kidnapping, among others. In the case of Argentina, following Roxin's doctrine of mediate authorship, the Court held that the crimes were committed by the military through the use of an organized power apparatus and emphatically dismissed allegations that such crimes were justified in the so-called "dirty war". Thus, the case against the Military Juntas has become a paradigmatic one, not only in Argentina, where many military leaders had to respond to criminal actions, but for all countries in the region that faced similar situations in recent history.

Keywords: HUMAN RIGHTS; CRIMINAL PROCEDINGS; ARGENTINA; MILITARY JUNTAS; JUDGMENTS; MEDIATE AUTHORSHIP.

"La Patria no hace al soldado para que la deshonre con sus crímenes, ni le da las armas para que cometa la bajeza de abusar de estas ventajas ofendiendo a los ciudadanos con cuyo sacrificio se sostiene; la tropa debe ser tanto más virtuosa y honesta cuando es creada para conservar el orden de los pueblos, afianzar el poder de las leyes y dar fuerza al gobierno para ejecutarlas y hacer que los malvados respeten porque serian más insolentes con el mal ejemplo de los militares"

José de San Martín (Ordenanzas militares especiales al Ejército de Cuyo, 1816)

\section{INTRODUÇ̃̃o}

De forma maquiavélica e provocadora, durante entrevistas realizadas entre outubro de 2011 e março de 2012, na cela $n^{0} 5$ na prisão federal de Campo de Mayo, em Buenos Aires, o genocida e ex-ditador Jorge Rafael Videla admitiu pela primeira vez que o governo que presidiu fez desaparecer entre sete e oito mil pessoas que sequestrou e torturou. Segundo o ex-ditador, era necessário cometer esses crimes "para que la sociedad no se diera cuenta ni pudiera provocar protestas dentro y fuera del país". Nesse sentido, "cada desaparición puede ser entendida ciertamente como el enmascaramiento, el disimulo, de una muerte" (VIDELA..., 2012).

A proposta deste artigo é analisar, em caráter preliminar, o caso do processo contra as juntas militares argentinas que levou à prisão os responsáveis por esses 
crimes hediondos. Esse processo tem um alto valor simbólico na luta pelo respeito aos direitos humanos na América Latina.

A complexidade do problema envolve vários temas, entre outros: a legítima luta contra a subversão, a tradicional posição de influência das forças armadas nos processos políticos latino-americanos, o que lhes garantia a impunidade, e a questão do retorno à democracia. Neste contexto, limitamos a temática ao processo judicial em si mesmo, que rompe o tabu da impossibilidade de julgar os comandantes militares e/ou chefes de governo das ditaduras latino-americanas.

Esta possibilidade ganha toda a relevância e atualidade no Brasil, onde se coloca a questão do direito à verdade sobre os desaparecidos na época da ditadura e a invalidação da Lei de Anistia no que tange aos crimes comuns de tortura, violação e/ ou sequestro, entre outros.

\section{A ordem do Presidente Alfonsín de processar as juntas militares}

O Presidente Raúl Alfonsín (10/12/1983-08/07/1989) teve o mérito de, três dias após assumir o governo argentino, começar a cumprir suas promessas de campanha, a saber: responsabilizar penalmente todos aqueles que violaram os direitos humanos durante o governo ditatorial, denominado com o eufemismo de Processo de Reorganização Nacional pelos militares, e também processar penalmente os dirigentes dos grupos subversivos como Montonersos e Ejército Revolucionário del Pueblo (ERP). Dessa forma, baixou os Decretos 167 e 158, ambos de 13 de dezembro de 1983, o primeiro para promover a ação penal contra ${ }^{1}$ Firmenich, Vaca Narvaja, Obregón Cano, Galimberti, Perdía, Pardo e Gorriarán Merlo, e o segundo para processar os membros das juntas militares que governaram a Argentina desde 24 de março de 1976: Jorge R. Videla, Orlando R. Agosti, Emilio A. Massera, Roberto E. Viola, Omar D. R. Graffigna, Armando J. Lambruschini, Leopoldo F. Galtieri, Basílio Lami Dozo e Jorge I. Anaya. ${ }^{2}$

1 Art. 1 Declárase la necesidad de promover la persecución penal, con relación a los hechos cometidos con posterioridad al 25 de mayo de 1973, contra Mario Eduardo Firmenich (L.E. 7.794.388); Fernando Vaca Narvaja (L.E. 7.997.198); Ricardo Armando Obregón Cano (L.E. 2.954.758); Rodolfo Gabriel Galimberti (C.I. 5.942.050); Roberto Cirilo Perdía (L.E, 4.399.488); Héctor Pedro Pardo (L.E. 7.797.669); y Enrique Heraldo Gorriarán Merlo (LE. 4.865.510) por los delitos de homicidio, asociación ilícita, instigación pública a cometer delitos, apología del crimen y otros atentados contra el orden público, sin perjuicio de los demás delitos de los que resulten autores inmediatos o mediatos, instigadores o cómplices. (ARGENTINA, 1983)

2 Art. 1 Sométase a juicio sumario ante el Consejo Supremo de las Fuerzas Armadas a los integrantes de la Junta Militar que usurpó el gobierno de la Nación el 24 de marzo de 1976 y a los integrantes de las dos juntas militares subsiguientes Teniente General Jorge R. Videla, Brigadier General Orlando R. Agosti, Almirante Emilio A. Massera, Teniente General Roberto E. Viola, Brigadier General Omar D. R. Graffigna, Almirante Armando J. Lambruschini, Teniente General Leopoldo F. Galtieri, Brigadier General Basilio Lami Dozo y Almirante Jorge I. Anaya. (ARGENTINA, 1983) 
Entre outros considerandos, o Decreto 158 afirma que a restauração da vida democrática deve atender, como uma de suas medidas prioritárias, à reafirmação da justiça como um valor ético fundamental. Com esse objetivo, devia-se procurar a propositura da ação penal contra os responsáveis de aprovar e supervisionar operações cuja execução tinha resultado na violação de direitos fundamentais da pessoa humana.

Esse Decreto, do ponto de vista das vítimas, teve a virtude de desenhar globalmente o plano criminoso e, do ponto de vista da cidadania, permitiu à Argentina, com esse processo, iniciar o penoso caminho de cura das feridas expostas causadas pela violação dos direitos humanos. Até então, esses crimes estavam encobertos pelas forças armadas e pela juntas militares.

Dessa forma, a ação penal teria como elemento fático, pelo menos, a comissão dos crimes de homicídio, privação ilegal de liberdade e aplicação de torturas aos detidos. Isso, sem prejuízo de outros crimes que aparecessem no curso da investigação.

Quanto ao processo penal, o Decreto afirma que seria aconselhável a adoção do procedimiento de juicio sumario en tiempos de paz, previsto no art. 502 do Código de Justiça Militar (ARGENTINA, 1951, p.89) para os casos em que seja necessária a repressão imediata de um crime para preservar a moral, a disciplina e o espírito militar das forças armadas. Ainda no art. 122, inciso 1 do mesmo Código, prescreve-se que, para esses casos, o tribunal competente é o Conselho Supremo das Forças Armadas; em grau de recurso haveria apelação ante a justiça civil, para a qual se enviaria imediatamente um projeto de lei ao Congresso Nacional, adicionando ao processo penal militar o referido recurso que não existia naquela época.

Entretanto, o Conselho Supremo das Forças Armadas negou-se a julgar seus pares.

\section{A acusação do Ministério Público}

O Fiscal (Promotor Público) de la Cámara de Apelaciones da Capital Federal, Julio Strassera, apoiando-se em mais de dois mil processos, selecionou 709 casos de violação dos direitos humanos por parte das forças armadas argentinas para reclamar justiça no que qualificou como: "el mayor genocidio que registra la joven historia de nuestro país”. (STRASSERA, 1985)

Afirmou que a violência não foi causada exclusivamente pela esquerda revolucionária: paralelamente a ela agia a Tríplice A, ou Aliança Anticomunista Argentina, grupo que utilizou a violência de maneira indiscriminada. Assim, a qualquer ação guerrilheira, a Tríplice A respondia com o assassinato de algum político ou intelectual de esquerda. (STRASSERA, 1985)

Como é sabido, no governo de Isabel Perón (01/07/74-24/03/1976), a figura forte era José Lopez Rega, ministro de Bem-Estar Social e secretário pessoal da presidenta, que financiou e sustentou politicamente a Aliança Anticomunista Argentina. 
O Fiscal Strassera, em sua acusação, nota que, a partir do golpe de Estado de 24 de março de 1976, a referida organização desaparece de cena, pela simples razão de que se integra ao Estado: "Porque la complicidad tolerante cedió paso a la acción directa, pasando sus miembros a revistar en los cuadros permanentes de la represión bajo la forma de las temibles patotas". (STRASSERA, 1985)

Em uma apertada síntese da volumosa acusação contra os membros das juntas militares argentinas (contida em 1.600 páginas, divididas em oito volumes, mais os documentos anexos ${ }^{3}$ ), o Dr. Strassera argumentou que, em virtude da virulência dos ataques da guerrilha, estava clara a necessidade e a legitimidade da repressão, com o fito de defender os valores da democracia. Entretanto, quando essa repressão traduz-se na adoção dos mesmos métodos criminais daquelas organizações, encontramo-nos em presença de outro terrorismo: o de Estado, que pratica os mesmos males que afirma combater.

Los guerrilleros secuestraban, torturaban y mataban. Y qué hizo el Estado para combatirlos? Secuestrar, torturar y matar en una escala infinitamente mayor y, lo que es más grave, al margen del orden jurídico instalado por él mismo, cuyo marco pretendía mostrarnos como excedido por los sediciosos. (STRASSERA, 1985). ${ }^{4}$

A acusação sublinhou que, no período em questão, se suprimiu o devido processo legal, substituindo-se a denúncia pela delação, a inquirição pela tortura e a sentença arrazoada pelo gesto neroniano do polegar para baixo. Assim a acusação deixava estabelecido que as juntas militares tinham fracassado, não somente na missão de estabelecer a inocência dos incriminados injustamente, mas também na de provar a culpabilidade dos responsáveis por atos criminosos. O Promotor Público notou que a falta de sentença judicial não é a omissão de uma formalidade apenas, é uma questão vital de respeito à dignidade do homem.

A violação à dignidade da pessoa humana começava com o sequestro, as torturas e o tratamento desumano; continuava com a sistemática mentira oficial de que não havia pessoas sequestradas em poder das forças armadas nem da polícia e, por-

\footnotetext{
3 Ao longo do processo, o material apresentado pelo Fiscal alcançou 7.800 folhas, divididas em 39 volumes. Para que o leitor possa ter uma ideia, somente as denúncias internacionais enviadas ao Tribunal pela representação argentina nas Nações Unidas em Genebra pesavam 700 kg. Evidentemente, nem todos os casos foram apresentados pela acusação. Em função do tempo e da complexidade, a Promotoria teve de fazer uma rigorosa seleção. Para outros detalhes da magnitude desse processo, ver Strassera.

4 Sobre os sequestros, torturas, desaparecimentos e mortes causadas pelas forças da repressão ver os documentos desclassificados do Departamento de Estado dos EUA: <http://www.desclasificados. com.ar/>. Ver também: <http://www.desaparecidos.org/arg/conadep/>; e o relatório final da Comisión Nacional Sobre la Desaparición de Personas en Argentina (CONADEP): <http://pt.scribd.com/ doc/256965/CONADEP-Nunca-masinforme-sobre-desaparecidos-en-Argentina1984>.
} 
tanto, não havia necessidade de proceder-se a uma investigação. Consequência de tudo isso era que os habeas corpus e outras medidas judiciais intentadas eram respondidos com informações falsas dos diferentes regimentos e/ou comandos militares e delegacias policiais, negando-se a reconhecer que as pessoas estavam, sim, detidas em recintos militares ou em lugares clandestinos em poder daqueles. De sorte que os familiares dos desaparecidos, ao longo de vários anos, viveram um verdadeiro calvário. Fazendo gestões para localizar seus parentes, bateram nas portas das unidades militares e policiais, pediram ajuda às embaixadas, rogaram apoio às igrejas e solicitaram informações a qualquer pessoa que pudesse ajudar. Tudo, porém, resultou infrutuoso. Lembremos também que a imprensa estava censurada e nada podia publicar ou comentar sobre o assunto. ${ }^{5}$

Nos autos consta que foram sequestrados bebês de alguns meses, jovens de 14 anos, uma anciã de 77, mulheres grávidas (que deram à luz na prisão e de cujos filhos não se sabe até agora), operários e empresários, camponeses e banqueiros, famílias inteiras, vizinhos de pessoas suspeitas, funcionários do Poder Executivo e do Judiciário, ex-ministros de Estado, militantes de partidos de esquerda etc. Qualquer um poderia ser devorado pelo sistema. Nesse sentido, abundantes provas foram carreadas aos autos: foram ouvidas 833 testemunhas (das quais 64 militares, 15 jornalistas, 13 sacerdotes e 12 estrangeiros); suas declarações estão contidas em 7.800 folhas, perfazendo 39 volumes.

As juntas militares chegaram ao cinismo de abrir um escritório para a busca de pessoas desaparecidas no Ministerio del Interior. O parquet anexou à peça acusatória mais de 5.500 pedidos de busca, nos quais se relatava a circunstância da detenção. Entretanto, em nenhum desses pedidos conseguiu-se localizar uma única pessoa que tivesse sido sequestrada por pessoal das forças armadas ou da polícia. Evidentemente, era tudo encenação. Os chefes militares abusaram da fragilidade em que se encontravam essas famílias em desespero pela ausência de um filho(a), pai ou mãe, neto ou neta, dando-lhes esperanças que sabiam de antemão serem vãs e inúteis.

Na peça acusatória o Fiscal Strassera acrescentou:

La mentira y el engaño con que los acusados despreciaron a la comunidad, se vuelven ahora como un bumerán contra ellos, pero además se extiende a sus subordinados tendiendo un manto de sospechas sobre ellos.

Sobre a censura à imprensa, o Tribunal, no Capítulo XIX do Segundo Considerando da sentença, item 5, cita testemunhos de vários jornalistas, de várias publicações, em relação a proibição da publicação de qualquer informação relacionada com desaparições, descobrimento de cadáveres, enfrentamentos armados e qualquer outro fato relacionado. 
Por eso debe individualizar-se y castigar a los responsables de las infamias cometidas para que no se equipare a quienes torturaron y robaron en beneficio propio, con los honestos. [...] Este proceso ha significado, para quienes hemos tenido el doloroso privilegio de conocerlo íntimamente, una suerte de descenso a zonas tenebrosas del alma humana, donde la miseria, la abyección y el horror registran profundidades difíciles de imaginar antes y de comprender después. [...] Por todo ello, señor presidente, este juicio y esta condena son importantes y necesarios para la Nación argentina, que ha sido ofendida por crímenes atroces. Su propia atrocidad torna monstruosa la mera hipótesis de la impunidad salvo que la conciencia moral de los argentinos haya descendido a niveles tribales, nadie puede admitir que el secuestro, la tortura o el asesinato constituyan "hechos políticos" o "contingencias del combate". (STRASSERA, 1985).

Dessa forma, o Dr. Strassera pediu as seguintes penas para os acusados, de acordo com os crimes imputados:

1. Jorge Rafael Videla: reclusão perpétua mais pena acessória pela autoria de 83 homicídios qualificados; 504 privações ilegais de liberdade qualificadas; 254 aplicaciones de tormentos $;{ }^{6} 94$ roubos com agravantes; 180 falsidades ideológicas de documento público; quatro usurpações; 23 reduções a condição análoga à de escravo; dois sequestros extorsivos; uma extorsão; uma supressão de documento; sete subtrações de crianças; sete aplicaciones de tormentos seguidas de morte. Tudo de acordo com o Código Penal argentino e diversas leis extravagantes.

2. Emilio Eduardo Massera: reclusão perpétua mais pena acessória pela autoria de 83 homicídios qualificados; 523 privações ilegais de liberdade qualificadas; 267 aplicaciones de tormentos; 102 roubos com agravantes; 201 falsidades ideológicas de documento público; quatro usurpações; 23 reduções a condição análoga à de escravo; uma extorsão; dois sequestros extorsivos; uma supressão de documento; 11 subtrações de crianças e sete aplicaciones de tormentos seguidas de morte. Tudo de acordo com o Código Penal argentino e diversas leis extravagantes.

3. Orlando Ramón Agosti: 88 homicídios qualificados; 581 privações de liberdade qualificadas; 278 aplicaciones de tormentos; 234 falsidades ideológicas; seis usurpações; 27 reduções a condição análoga à de escravo; uma extorsão; dois sequestros extorsivos; uma supressão de documento;

6 Poderia ser traduzido como "tortura", mas preferimos deixar o original pela força da expressão "aplicación de tormentos" que se entende bem em português. 
11 subtrações de crianças; e sete aplicaciones de tormentos seguidas de morte. Tudo de acordo com o Código Penal argentino e diversas leis extravagantes.

4. Roberto Eduardo Viola: reclusão perpétua pela autoria de cinco homicídios qualificados; 152 privações ilegais de liberdade qualificadas; 49 aplicaciones de tormentos; 17 roubos com agravantes; 105 falsidades ideológicas de documento público; uma usurpação; 32 reduções a condição análoga à de escravo; e uma subtração de criança. Tudo de acordo com o Código Penal argentino e diversas leis extravagantes.

5. Armando Lambruschini: reclusão perpétua pela autoria de cinco homicídios qualificados; 117 privações ilegais de liberdade qualificadas; 35 aplicaciones de tormentos; oito roubos com agravantes; 98 falsidades ideológicas de documento público; uma usurpação; 32 reduções a condição análoga à de escravo; e uma subtração de criança. Tudo de acordo com o Código Penal argentino e diversas leis extravagantes.

6. Leopoldo Fortunato Galtieri: 15 anos de prisão pela autoria de 11 privações ilegais de liberdade qualificadas; uma aplicación de tormentos; 17 falsidades ideológicas de documento público; uma usurpação; 8 reduções a condição análoga à de escravo; 217 encobrimentos de crimes. Tudo de acordo com o Código Penal argentino e diversas leis extravagantes.

7. Omar Rubens Graffigna: 15 anos de prisão pela autoria de 34 privações ilegais de liberdade qualificadas; 15 aplicaciones de tormentos; 67 falsidades ideológicas de documento público; uma usurpação; 18 reduções a condição análoga à de escravo; 172 encobrimentos de crimes e uma subtração de criança. Tudo de acordo com o Código Penal argentino e diversas leis extravagantes.

8. Jorge Isaac Anaya: 12 anos de prisão pela autoria de 3 falsidades ideológicas de documento público; uma privação ilegal de liberdade qualificada; uma usurpação; uma redução a condição análoga à de escravo; e 217 encobrimentos de crimes. Tudo de acordo com o Código Penal argentino e diversas leis extravagantes.

9. Basilio Lami Dozo: dez anos de prisão pela autoria de uma privação ilegal de liberdade qualificada; uma falsidade ideológica de documento público; uma usurpação; uma redução a condição análoga à de escravo; 217 encobrimentos de crimes. Tudo de acordo com o Código Penal argentino e diversas leis extravagantes.

Isto tudo seguindo a doutrina da autoria mediata, ou da utilização de um aparato organizado de poder, tese que não foi confirmada pela Corte Suprema de Justicia de 
La Nación, porém foi aceita pela Câmara Federal que julgou o caso. O Ministério Público perguntou: "Quem é o autor dos fatos delitivos que se cometem mediante a utilização de um aparato organizado de poder? Ou pode ser considerado autor dos fatos delitivos cometidos no seio de um aparato organizado de poder o que dirige essa estrutura, ainda que não tenha participado materialmente na sua execução?” A essas indagações respondeu afirmativamente.

Caracterizou primeiramente a expressão "aparato organizado de poder" como uma estrutura encabeçada por um centro de decisões a partir do qual se dão as ordens para a execução de atos ilícitos. A chefia destes tipos de organização domina os fatos de tal maneira que, uma vez tomada a decisão para que ocorra determinado crime, este acontece sem necessidade de que se conheçam seus executores diretos. Na hipótese de que alguém não cumpra a ordem, outro se encarregará de executá-la em seu lugar. Em outras palavras, independentemente da vontade de quem execute os atos, existe uma vontade superior que, de qualquer forma, fará que a execução da conduta criminosa seja levada a cabo. O domínio do fato não se dá por meio do simples domínio da vontade do terceiro, mas mediante o domínio da estrutura de poder no qual a vontade do terceiro é irrelevante. Aparece assim a figura do mandante, o "autor de escritório", que controla a execução do ato criminoso, dando lugar à figura do "autor detrás do autor".

Dado o incipiente desenvolvimento da doutrina da autoria mediata e do direito penal internacional naqueles dias, o Promotor Público realizou continuados esforços para convencer os juízes da admissibilidade da inserção dos autores de escritório entre as categorias de autores, admitido pelo art. 45 do Código Penal argentino. Assim passou revista a diversas doutrinas, como a dos autores por determinação, coautoria, instigação, perpetradores e cúmplices, e à tradicional autoria de quem dá ordens que conduzem à realização de um delito do art. 514 do Código de Justiça Militar (ARGENTINA, 1951), para finalizar dizendo:

\footnotetext{
Señores jueces: quiero renunciar expresamente a toda pretensión de originalidad para cerrar esta requisitoria. Quiero utilizar una frase que no me pertenece, porque pertenece ya a todo el pueblo argentino. Señores jueces: nunca más. ((STRASSERA, 1985)
}

\section{A SEnTenÇa}

Depois de desestimar as questões incidentais levantadas, de relatar a atuação das organizações guerrilheiras na Argentina no período em questão e de analisar a reação do governo constitucional contra a guerrilha, o tribunal passou a fazer uma análise pormenorizada da reação dos governos militares ante as atividades subversivas. 


\section{A REAÇÃo dos GoVERnOS MILITARES diANTE DA SUbVERSÃo: AÇõES ILEGAIS A PARTIR do GOLPE DE 24 DE MARÇO DE 1976}

Resultou provado que, após o golpe de Estado de 24 de março de 1976, houve um aumento significativo do número de desaparecimento de pessoas em todo o território argentino; desses fatos, o Tribunal inferiu um quadro grave, preciso e concordante do aumento do número de pessoas privadas clandestinamente de sua liberdade (Capítulo XI, do Segundo Considerando). No Quarto Considerando da sentença são apresentados, com nomes e sobrenomes, os casos de aproximadamente setecentas pessoas. (ARGENTINA, 1985)

Esses fatos tinham uma série de características comuns, a saber:

i) os sequestradores eram membros das forças armadas ou da polícia, sendo que adotavam precauções para não serem identificados, usando perucas, gorros e outros disfarces;

ii) outra das características era a intervenção de várias pessoas fortemente armadas nessas operações;

iii) as referidas operações ilegais realizavam-se com um aviso prévio à autoridade da zona em que se produziam. Solicitava-se "área livre", o que permitia que se efetuassem invasões de domicílio, sequestros etc., sem a interferência policial, uma vez que poderia acontecer a eventualidade de que a polícia fosse chamada para intervir. Em muitas ocasiões esses grupos armados contavam com o apoio da própria polícia para realizar seus crimes;

iv) os sequestros ocorriam, em geral, de noite, na residência das vítimas, sendo que, simultaneamente, se saqueava também a casa. Somente a venda de imóveis de propriedade das vítimas, falsificando os títulos de propriedade e os documentos necessários, permitiu-lhes, em pouco tempo, acumular fortuna considerável;

v) as vítimas eram levadas em veículos, sendo-lhes impedido de ver ou comunicarem-se. Além disso, adotavam-se medidas para ocultá-las dos vizinhos e do público em geral.

As pessoas sequestradas eram levadas imediatamente a dependências secretas dentro de unidades militares ou da polícia. Nos autos (Capítulo XII do Segundo Considerando), são relacionados os inúmeros centros de detenção dependentes do exército, da Polícia Federal, das Polícias Provinciais, de unidades penitenciárias, da armada e da força aérea. (ARGENTINA, 1985)

Nesses centros clandestinos de detenção, os sequestrados recebiam tratamento desumano e eram interrogados com métodos de tortura (notadamente golpes, força elétrica e asfixia), de acordo com o capítulo XIII do Segundo Considerando da sentença: 


\begin{abstract}
Durante el secuestro, se imponía a los cautivos condiciones inhumanas de vida, que comprendían a muchos el déficit casi total de alimentación, el alojamiento en lugares insalubres, en los que no podían sustraerse de percibir los lamentos o ruidos que se producían al torturarse a otros cautivos y el permanente anuncio, a través de hechos y de palabras, de que se encontraban absolutamente desprotegidos y exclusivamente a merced de sus secuestradores. [...] La llegada a un lugar desconocido donde casi siempre recibían de inmediato los golpes o la tortura; el alojamiento en "cuchas", "boxes", "tubos", sobre un jergón o directamente en el suelo; el descubrimiento de que había otras personas en igual situación que llevaban largo tiempo así; la incógnita sobre cuál sería el desenlace y cuánto duraría; las amenazas de toda índole; la escasa y mala comida; la precariedad cuando no la ausencia de medios para satisfacer las necesidades fisiológicas; la falta de higiene y de atención médica; los quejidos; el desprecio y maltrato de los guardias; y todas las demás vivencias que fueron relatadas con detalle en el curso de la audiencia. (ARGENTINA, 1985)
\end{abstract}

As vítimas desses fatos tiveram diversa sorte:

i) algumas, depois de um período maior ou menor, eram postas em liberdade com a expressa proibição de contar o sucedido, e submetidas a controle por parte de seus sequestradores (visitas, chamadas telefônicas etc.);

ii) outras foram postas à disposição do Poder Executivo, sendo promovidas contra elas diversas ações, ocultando-se o período de detenção clandestina;

iii) entretanto, a maioria das pessoas ilegalmente detidas permanece desaparecida até os dias de hoje. Nos autos aparece uma extensa lista corroborada pelo levantamento da Conadep, que no anexo do livro Nunca más apresenta a relação de 8.961 pessoas desaparecidas. (ARGENTINA, 1985)

O Capítulo XVI do Segundo Considerando da sentença é uma longa exposição de fatos vinculados com as desaparições, que conduzem a inferir que os desaparecidos foram eliminados fisicamente. Com efeito, há relatos de que em setores litorâneos, nos últimos meses de 1978 e começos de 1979, o mar lançou à praia muitos cadáveres. Há também uma longa série de denúncias de sepultamento de cadáveres sem identificação em diferentes localidades argentinas trazidos por autoridades militares ou policiais. Em muitos casos, os sequestrados foram sedados e lançados ao mar ou rios. (ARGENTINA, 1985)

Nos Capítulos XVIII e XIX do Segundo Considerando da sentença, analisa-se o grande número, (14.756) de habeas corpus impetrados entre 1976 e 1982, todos rejeitados, uma vez que as autoridades militares e/ou policiais negavam-se, metodicamente, a informar sobre a detenção dessas pessoas. (ARGENTINA, 1985) 
Em virtude disso, entre 1976 e 1983, iniciaram-se inúmeras ações pelo crime de privação ilegal de liberdade em todo o país, totalizando 9.319 processos. Considerando somente a Capital Federal, entre março de 1974 e 1982, os processos por esse delito elevaram-se a 4.023. Em resumo, esses crimes foram cometidos em todo o território nacional, ainda que não de maneira uniforme. A comissão de privações ilegais de liberdade aconteceu justamente nas áreas prioritárias de ação das forças armadas contra a subversão.

Fracassada a via judicial, os familiares continuaram sua via crucis perante diversas autoridades do Poder Executivo, inclusive perante o comandante chefe do Exército e presidente da Nação, Jorge Rafael Videla, como está fartamente documentado nos autos.

Como nada disso surtiu efeito, o clamor das famílias chegou a diversas organizações internacionais de caráter público e privado ${ }^{7}$ e a diversos governos estrangeiros, ${ }^{8}$ que fizeram chegar às respectivas juntas militares ao longo do período os correspondentes pedidos, reclamações e denúncias. Diante dessa onda de reclamações, os diversos governos militares omitiram-se na realização de qualquer investigação séria e adequada em virtude da gravidade dos fatos denunciados.

O Tribunal notou, outrossim, que as diversas juntas militares demonstraram um propósito deliberado de ocultar a verdade das desaparições, atribuindo tais denúncias a uma campanha internacional contra a Argentina.

\section{A Guerra Suja alegada como justificativa}

Entre as justificativas alegadas pelos comandantes militares para outorgar juridicidade às suas ações, temos o argumento da guerra suja, isto é, de que teria havido na Argentina uma guerra não convencional, e de que todas as guerras produzem, no calor da contenda, feitos cruéis que, muito embora não desejados, são uma consequência necessária da situação belicosa.

Este argumento foi esgrimido por todas as ditaduras na América Latina, e por isso merece ser conhecida a posição do Tribunal a respeito.

\footnotetext{
7 Por exemplo, a Organização dos Estados Americanos, a Comissão de Direitos Humanos das Nações Unidas, a Cruz Vermelha Internacional, o Conselho Mundial de Igrejas, a União Mundial Democrata Cristã, o Comitê Internacional de Juristas para os Direitos Humanos, a Federação Mundial de Direitos Humanos, a Federação Internacional de Mulheres Democráticas, a Anistia Internacional etc.

8 Como as gestões feitas pelos governos da República Federal Alemã, Romênia, Dinamarca, Suécia, Argélia, Canadá, Peru, Bulgária, URSS, Portugal, Bélgica, Líbano Polônia, Israel, Turquia, Islândia, Bolívia, Vaticano, Iraque, Brasil, Colômbia, Equador, El Salvador, Holanda, Suíça, Cuba, Irã, Japão, Irlanda, Hungria, EUA, Espanha, Itália, China Nacionalista, Grécia, Finlândia, Chile, Arábia Saudita, Noruega, Nicarágua, Índia, Panamá, Nova Zelândia, Venezuela, Áustria, Grã-Bretanha e França.
} 
Primeiramente, os insignes julgadores passaram revista aos diferentes tipos de guerra citados na literatura, desde a Guerra Civil Nacional, passando pela Guerra Civil Internacional, até a Guerra Revolucionária.

Considerando os volumosos antecedentes trazidos ao processo e analisando as características que assumiu o fenômeno terrorista na Argentina, chegaram à conclusão de que se tratou de uma guerra revolucionária. Um relatório do Estado Mayor General del Ejército argentino ${ }^{9}$ afirma que esta teria chegado à fase de domínio de um espaço geográfico determinado como passo prévio à instalação de um governo revolucionário. Entretanto a Directiva $n^{0} 333 / 75$, Operaciones contra la subversión en Tucumán, estabelece que o inimigo (entre 300 a 500 homens) preparava-se para a abertura de uma frente rural, descrevendo atividades tão somente preparatórias.

O Tribunal assinalou que

en momento alguno, tales grupos insurgentes, fueron reconocidos como beligerantes, recibieron reconocimiento internacional, contaron con la capacidad de dictar normas con alguna eficacia general, y menos aún tuvieron poder de hecho, para aplicarlas, ni hubo intervención en el conflicto de potencia extranjera alguna. (ARGENTINA, 1985)

Contudo, mesmo que a guerra revolucionária tivesse atingido uma fase avançada, o Estado estava sujeito a normas jurídicas e éticas para fazer frente ao conflito; em outras palavras, a repressão tinha de ter determinado alcance e limites definidos de acordo com a constitucionalidade vigente à época.

Hoje, o ex-ditador Jorge Rafael Videla afirma que os Decretos 2.770, 2.771 e 2.772 de 6/10/1975 outorgavam às forças armadas "todo el poder y competencias para desarrollar nuestro trabajo e incluso excedían lo que habíamos pedido; Luder, prácticamente, nos había dado una licencia para matar" (ANGOSO, 2012).

O presidente interino, Ítalo Argentino Luder, porém, que assinou esses decretos e testemunhou no processo, desmente. Ele declarou que essas normas de maneira nenhuma supõem a repressão fora da lei, simplesmente dispunham sobre a contribuição que dariam as forças armadas para salvaguardar a ordem institucional. Ante uma pergunta do Promotor Público, de que, se nas discussões prévias, a assinatura dos decretos considerava imprescindível a opção de métodos extraordinários para combater a subversão, como a privação ilegítima da liberdade, a obtenção da informação a qualquer custo e inclusive a supressão física dos subversivos, o Dr. Luder foi enfático no sentido de que os decretos tinham somente o objetivo de: "requerir la colaboración de la Fuerzas Armadas para la lucha contra la subversión. Se mantenía toda la

9 Cuaderno de Prueba del Teniente General Viola, p. 486-496. Cf. com o considerando Sexto da sentença. (ARGENTINA, 1985) 
normativa, las garantías individuales y sobre todo el debido proceso para sancionar a los que estuvieran incursos en algún delito dentro del accionar subversivo". ${ }^{10}$

Hoje o ex-ditador reconhece com cinismo e insensibilidade que o eufemismo sob o qual se ocultaram os crimes era: "Disposición Final", duas palavras que segundo ele no jargão militar significam "sacar de servicio una cosa por inservible, por ejemplo, una ropa que ya no se usa o no sirve porque está gastada" (NOS DECIAN..., 2012).

Dessa forma, os referidos decretos foram interpretados pelos chefes militares como licenças para matar, e não somente isso, mas como autorização para desconhecer os direitos das pessoas a ponto de tratá-las como roupa usada inservível.

Para o Tribunal, ficou claro que, para reprimir insurretos ou subversivos, cabem duas possibilidades: ou aplicam-se as leis de direito interno, ou as normas do direito internacional, porém não se pode admitir que, para fazer frente a uma agressão terrorista, se argumente que se está diante de uma guerra na qual não vigora nem o direito, nem a moderação, nem os princípios éticos, religiosos ou humanos. Não é possível aceitar que o fim justifique os meios, nem que todos eles são nobres quando o fim é nobre.

$\mathrm{Na}$ sentença sublinha-se que é inadmissível admitir que um governo de fato, que concentrou em suas mãos amplas faculdades legiferantes, que se arrogou inclusive o poder constituinte, não tenha tido outra forma de combater o terrorismo a não ser por meio do terror e da clandestinidade, fora de toda referência normativa. Assim o Tribunal afirma, de maneira eloquente, que nenhum fenômeno de violência, por mais terrível que seja, pode ser tratado fora dos marcos do direito.

\section{O DisPOSITIVO DA SENTENÇA}

Os Juízes da Cámara Nacional de Apelaciones en lo Criminal y Correccional Federal de la Capital Federal, Andrés J. D’Alessio, León Carlos Arslanián, Ricardo Gil Lavedra, Guillermo Ledesma, Jorge Torlasco e Jorge Valerga Aráoz condenaram o teniente general Jorge Rafael Videla a reclusão perpétua, muito embora tenha sido absolvido de vários crimes de que fora acusado; condenaram o almirante Emilio Eduardo Massera a prisão perpétua, muito embora tenha sido absolvido de vários delitos de que fora acusado; condenaram o brigadier General Orlando Ramón Agosti a quatro anos e seis meses de prisão; foi, entretanto, absolvido de inúmeros crimes dos quais era acusado; condenaram também o teniente general Roberto Eduardo Viola a 17 anos de prisão, muito embora também tenha sido absolvido de vários

${ }_{10}$ Cf. Asociación nunca más. Testimonios. Luder, Italo. Disponível em: http://memoriadebida.org/content/luder-italo. Acesso em: 14 abr. 2012. 
crimes; condenaram o almirante Armando Lambruschini a oito anos de prisão e ele foi absolvido de numerosos delitos que lhe eram imputados; absolveram também de todos os crimes imputados o brigadier general Omar Domingo Graffigna, o teniente general Leopoldo Fortunato Galtieri, o almirante Jorge I. Anaya e o brigadier general Basilio Lami Dozo.

\section{Considerações Finais}

É impossível, no âmbito de um artigo, fazer um levantamento das violações aos direitos humanos cometidas durante o período entre o golpe de Estado de março de 1976 e a Guerra das Malvinas em 1982. O informe da Conadep (s.d.) oferece-nos uma visão geral do sofrimento das vítimas e de seus familiares.

O primeiro processo movido contra os responsáveis por esses crimes foi este famoso Juicio a las juntas militares, que o Dr. Strassera, Promotor Público que apresentou a acusação, descreve como um tipo de "descenso a zonas tenebrosas del alma humana, donde la miseria, la abyección y el horror registran profundidades difíciles de imaginar antes y de comprender después". ((STRASSERA, 1985)

A derrota do exército argentino na Guerra das Malvinas e a ascensão do presidente Alfosín à Presidência da República Argentina permitiram as condições políticas para o julgamento por meio dos Decretos 167 e 158 de 1983.

O Tribunal, seguindo a doutrina de Roxin da autoria mediata, considerou que os crimes foram cometidos mediante a utilização de um aparato organizado de poder e afastou de maneira enfática as alegações de que os delitos teriam justificação em uma alegada guerra suja.

Assim, este processo contra as juntas militares argentinas passou a ser um caso paradigmático, não somente no próprio país platino, em que muitos chefes militares tiveram que responder (ou estão respondendo) a ações criminais pelos delitos cometidos e/ou encontram-se cumprindo pena em virtude deles, mas também na América Latina, onde encontramos vários países, como é o caso do Brasil, em que houve violações graves dos direitos humanos e devem ser levados a cabo processos tendentes à busca da verdade e da justiça.

\section{REFERÊNCIAS}

AMBOS, K.; MALARINO, E. (Eds.) Persecución penal nacional de crímenes internacionales en América Latina y España. Montevideo: Fundación Konrad Adenauer Uruguay, 2003. 
AMBOS, K.; MALARINO, E.; WOISCHNIK, J. (Eds.) Temas actuales del derecho penal internacional. Montevideo/Berlin: Fundación Konrad Adenauer Uruguay, 2005.

AMBOS, K.; MALARINO, E.; ELSNER, G. (Eds.) Jurisprudencia latinoamericana sobre derecho penal internacional. Montevideo/Berlin: Fundación Konrad Adenauer Uruguay, 2008.

ANGOSO, R. No salimos a cazar pajaritos, sino al terrorismo y a los subversivos. Cambio 16. 4 mar. 2012. Disponível em: <http://cambio16.es/not/1344/_ldquo_ no_salimos_a_cazar_pajaritos__sino_al_terrorismo_y_a_los_subversivos_rdquo__ . Acesso em: 14 abr. 2012.

ARGENTINA. Cámara de Apelaciones del principalísimo distrito Capital. Disponível em: $<$ http://www.desaparecidos.org/arg/doc/secretos/fiscal02.htm $>$. Acesso em 26 jun. 2014.

. Poder Judiciário de la Nación. Causa originariamente instruída por el Consejo Supremo de las Fuerzas Armadas en cumplimiento del Decreto 158/83 del Poder Ejecutivo Nacional. Causa $N^{\circ}$ 13/84. Buenos Aires, 9 de diciembre de 1985. Disponível em: $<$ http://www.derechos.org/nizkor/arg/causa13/index.html $>$. Acesso em: 26 jun. 2014.

. Codigo de Justicia Militar. Ley 14.029, de julio de 1951. Disponível em: < http://pdba.georgetown.edu/Security/citizensecurity/argentina/leyes/codigojusticiamilitar.pdf $>$. Acesso em: 26 jun. 2014.

. Decreto No. 158, de 13 de diciembre de 1983. Disponível em: < http:// www.desaparecidos.org/arg/doc/secretos/orden02.htm>. Acesso em: 26 jun.2014.

. Decreto No. 167, de 13 de diciembre de 1983. Disponível em: $<\underline{\text { http:// }}$ www.desaparecidos.org/arg/doc/secretos/tesis02.htm > . Acesso em: 26 jun. 2014.

. Sentencia: condena y absoluciones. Juicio a los comandantes en jefe. Extracto. (1985) Disponível em: $<$ http://www.desaparecidos.org/arg/doc/secretos/ conde.html>. Acesso em: 26 jun. 2014.

ASOCIACIÓN NUNCA MÁS. Testimonios. Luder, Italo. Fecha del testimonio: 1985-04-22. Disponível em: $<$ http://memoriadebida.org/content/luder-italo $>$. Acesso em 26 jun. 2014.

BARRIENTOS-PARRA, J. O Caso Pinochet e a universalização da luta pelos Direitos Humanos. Revista dos Tribunais, São Paulo, ano 100, v. 763, p. 425-474, mai. 1999. 
. O Caso Fujimori: exemplo de superação da impunidade em América Latina. Revista Estudos Jurídicos Unesp, Franca, ano 14, n. 19, p. 199-213, 2010.

. O direito penal internacional e os crimes contra a humanidade cometidos pelo Estado ou por indivíduos com a conivência estatal. Revista de Informação Legislativa, Brasília, ano 48, n. 192, p. 31-42, out.-dez. 2011a.

. Crimes contra a humanidade cometidos pelo Estado ou por indivíduos com a conivência estatal à luz do direito interno e internacional. Revista dos Tribunais, São Paulo, ano 100, v. 903, p. 383-410, jan. 2011b.

BRASIL. Lei No. 6.683, de 28 de agosto de 1979 (Lei de Anistia). Disponível em: $<$ http://www.planalto.gov.br/ccivil_03/leis/16683.htm>. Acesso em: 26 jun. 2014.

CANÇADO TRINDADE, A. A. Evolução e fortalecimento da proteção internacional dos direitos da pessoa humana em sua ampla dimensão. In: CANÇADO TRINDADE, A. A. (Ed.). Proteção dos direitos humanos nos planos nacional e internacional: perspectivas brasileiras. San José de Costa Rica/ Brasília: Instituto Interamericano de Direitos Humanos/F. Naumann-Stiftung, 1992.

CONADEP - Comisión Nacional sobre la Desaparición de Personas. Informe "Nunca Más". Derechos Humanos.net. s.d. Disponível em: < http://www.derechoshumanos.net/lesahumanidad/informes/argentina/informe-de-la-CONADEP-Nunca-mas. htm>. Acesso em: 14 abr. 2012.

FRAIDENRAIJ, S. Direito internacional humanitário e os direitos humanos à luz de um caso particular. In: CANÇADO TRINDADE, A. A. (Ed.). Proteção dos direitos humanos nos planos nacional e internacional: perspectivas brasileiras. San José de Costa Rica/ Brasília: Instituto Interamericano de Direitos Humanos/F. Naumann-Stiftung, 1992.

NOS DECÍAN 'se quedaron cortos'. Pagina 12. 14 abr. 2012. Disponível em: $<$ http:// www.pagina12.com.ar/diario/elpais/1-191859-2012-04-14.html>. Acesso em: 14 abr. 2012.

PARENTI, P. F. Informes nacionales: Argentina. Jurisprudencia latinoamericana sobre derecho penal internacional. AMBOS, K.; MALARINO, E.; ELSNER, G. (Eds.). Montevideo: Fundación Konrad Adenauer Uruguay, 2008.

PIOVESAN, F. Direitos humanos e o direito constitucional internacional. São Paulo: Saraiva, 2009.

RAMOS, A. Responsabilidade internacional por violação de direitos humanos. Rio de Janeiro: Renovar, 2004. 
STRASSERA, J.C. La acusación: lucimiento de un fiscal (1985). Proyecto Desaparecidos. Disponível em: $<$ http://www.desaparecidos.org/arg/doc/secretos/fiscal02. htm>. Acesso em: 4 jul. 2011.

VIDELA: "Pongamos que eran siete mil u ocho mil las personas que debían morir".

Página 12, 13 abr. 2012. Disponível em: <http://www.pagina12.com.ar/diario/ultimas/20-191810-2012-04-13.html>. Acesso em: 13 abr. 2012.

Submetido em: 3-2-2014

Aceito em: 23-6-2014 